Portland State University

PDXScholar

2-23-1972

\title{
Comparison of Amounts of Verbal Response Elicited by a Speech Pathologist and a Mother in the Clinic
}

Sherry Lee Nelson

Portland State University

Follow this and additional works at: https://pdxscholar.library.pdx.edu/open_access_etds

Part of the Speech and Hearing Science Commons, and the Speech Pathology and Audiology Commons

Let us know how access to this document benefits you.

\section{Recommended Citation}

Nelson, Sherry Lee, "Comparison of Amounts of Verbal Response Elicited by a Speech Pathologist and a Mother in the Clinic" (1972). Dissertations and Theses. Paper 1585.

https://doi.org/10.15760/etd.1584

This Thesis is brought to you for free and open access. It has been accepted for inclusion in Dissertations and Theses by an authorized administrator of PDXScholar. Please contact us if we can make this document more accessible: pdxscholar@pdx.edu. 
AN ABSTRACT OF THE THESIS OF Sherry Lee Nelson for the Master of Science in Speech: Emphas is in Speech Pathology/Audiology presented February 23, 1972.

Title: Comparison of Amounts of Verbal Response Elicited by a Speech Pathologist and a Mother in the Clinic.

APPROVED BY MEMBERS OF THE THESIS COMMITTEE:

1

Robert L. Cás)eel, Chairman

Róbert H. English

Louise P. Feldman

One of the primary responsibilities of a speech pathologist is the assessment of a chilt's language. Many studies have been done in the area of language development. The results of these studies have varied causing concern among researchers over the validity of the data gathered. Many factors that could affect the results of previous research have been investigated. Until recently, however, there has been relatively little research about the effects of examiner differences on the results of language assessments.

Research in the area of examiner differences has resulted in the discovery of factors which could affect the results of language assessments and, more specifically, Mean Length of Response (MLR). McGuigan (1963) suggested the interaction of the examiner's personality 
characteristics and the independent variable. Cowan, et al., (1963) suggested examiner and stimulus variables could affect the subject according to the age and sex of the child. Wilson (1969) stated that there was no standardization for an examiner's method of eliciting a language sample or for the stimulus materials used by the examiner. Castee i (1969) suggested an interaction between the examiner and the setting of the examination. He concluded that the best results were obtained when the examiner was in his most comfortable setting (the mother in the home and the speech pathologist in the clinic). A study by Mathis (1970) substantiated the results of the study by Casteel (1969). Mathis concluded that the speech pathologist elicits as representative a language sample from the child in the clinic as the mother elicits from the child in the home.

The purpose of this study was to discover to what extent the MLR of children will differ when elicited by two examiners, the speech pathologist and the mother, who are in the clinical setting.

Fourteen children, four years of age, were examined in the clinical setting by the speech pathologist and the mother. Twenty-eight 15-minute tape recorded conversations were transcribed, the MLR tabulated, and the results analyzed statistically by means of the t-test for significance. The Spearman Rank Correlation Coefficient was used to compare the consistency of each child's performance with that of his peers from one examination to another.

The results indicate that there is a statistically significant difference between the amount of language elicited by the speech pathologist and the mother in favor of the speech pathologist when the 
examination takes place in the clinical setting. The .05 level of confidence was established for this test.

When the MLR average of the black children was compared to the MLR average of the white children, the difference between the two groups was not found to be significant at the .05 level of confidence. There was a trend, however, for the white children to display a higher MLR average than the black children. The comparison of MLR averages between two socio-economic groups in this study resulted in a difference that was not significant at the .05 level of confidence. When MLR was analyzed according to the order of examination, there was no significant difference between the first and second examination. The girls in this study achieved a higher MLR average than that achieved by the boys in this study. The results of this study also indicated that a child's performance will be consistent when compared to the performance of other children when both the speech pathologist and the mother examine the child in the clinical setting. The MLR averages of this study were lower than the normative data. The differences could be a result of factors not identified at this time. 


\section{COMPARISON OF AMOUNTS OF VERBAL RESPONSE \\ ELICITEO BY A SPEECH PATHOLOGIST AND A \\ MOTHER IN THE CLINIC}

by

SHERRY NELSON
A thesis submitted in partial fulfillment of the requirements for the degres of
MASTER OF SCIENCE
in
SPEECH: EMPHASIS IN SPEECH PATHOLOGY/AUOIOLOGY

Portland State University

1972 
TO THE OFFICE OF GRADUATE STRDIES:

The members of the Commitiee approve the thesis of Sherry Lee Nelson presented February 23, 1972.

Robert L. Casteél, Chairman

Robert H. Engiish

Louise Feldman

APPROVED :

Rdbert W. Vogelsafy, Head, Dpartment of speech

Bavid T. Ciark, Dean of Graduate Studies 


\section{ACKNOWLEDGMENTS}

It is with particular appreciation that I acknowledge my chairman, Dr. Robert L. Casteel, for his continual help and encouragement throughout this project.

A special thanks to Dr. Nancy Marshall, who served as my examining speech pathologist in this study; to Dr. Jack Hegrenes for his many hours of help on the statistics in this study; to Jan Leininger for her assistance with the psychological screening of the subjects in this study; and to Sally Prichard, who helped in too many ways to enumerate.

Finally, because he has influenced the completion of this project the most, I thank my husband, Mike. 
TABLE OF CONTENTS

PAGE

ACKNOWLEDGMENTS . . . . . . . . . . . . . . . i i i

LIST OF TABLES ..................... . . . . . vi

LIST OF FIGURES . . . . . . . . . . . . . . . . . . vii vi vi

CHAPTER

1 REVIEW OF LITERATURE AND STATEMENT OF

PROBLEM . . . . . . . . . . . . . . . 1

Introduction . . . . . . . . . . . 1

Review of the Literature ........ 2

Purpose of the Study . . . . . . . . 7

1! METHODS AND PROCEDURES . . . . . . . . . 8

Procedures ............. 8

Subjects............... . . 9

Examiners ............ 10

Test Sessions ............ . 11

Setting ............... 11

Transcripts . . . . . . . . . 12

MLR Analysis.............. 12

Reliability ............. 13

Data Analysis ......... . . . 14

II RESULTS AND DISCUSSION . . . . . . . . . . 15

Results.............. 
CHAPTER

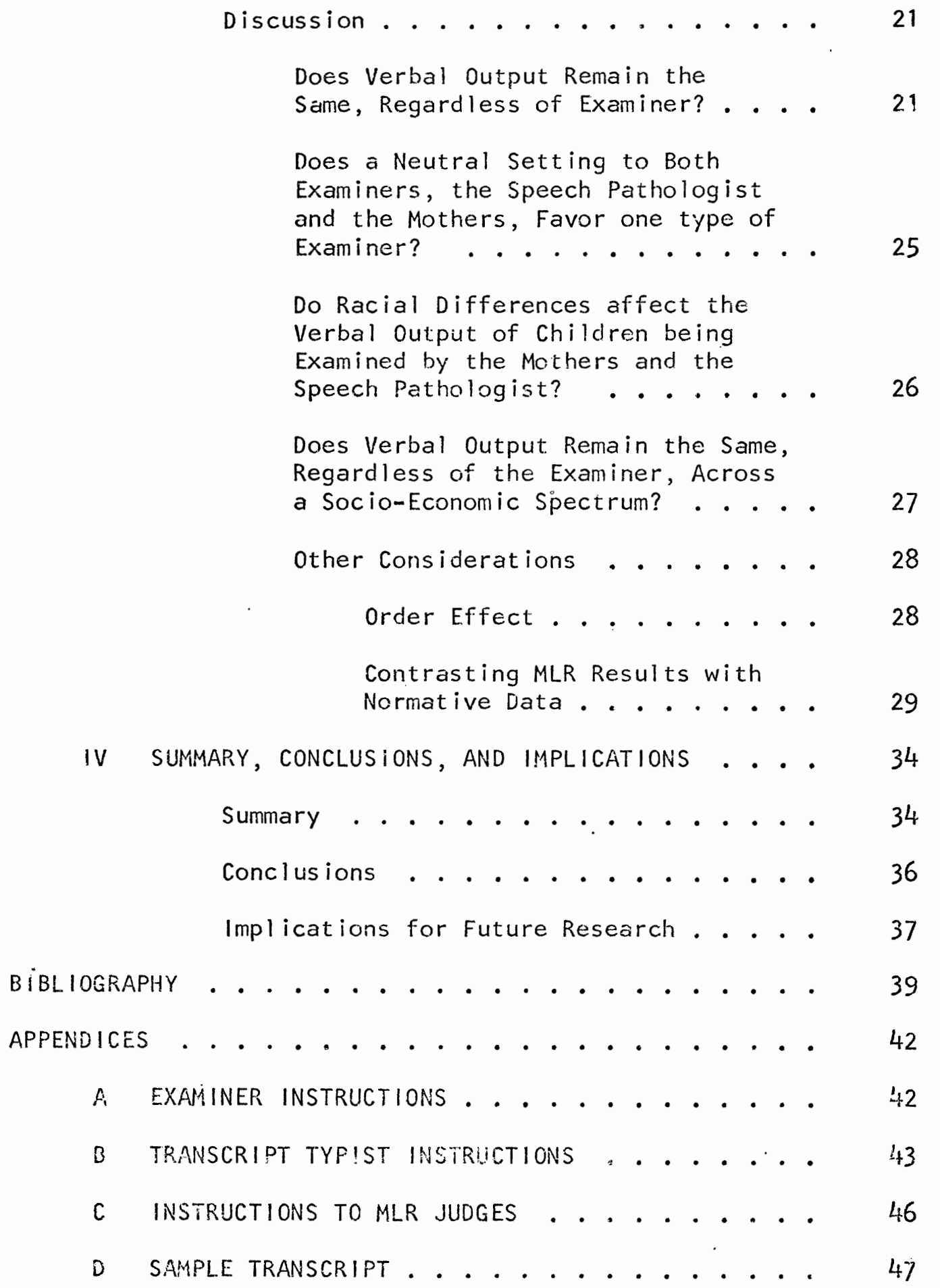




\section{LIST OF TABLES}

TABLE

PAGE

1 MLR Obtained by Each Examiner and Differences Individuaily and Collectively . . . . . 16

II t-Ratio When Comparing MLR of Children Examined

by Speech Pathologist and Mother, Black

Children and White Children, High and Low

Socio-Economic Groups, and First and Second

Examination ........... 18

III Subjects Ranked by MLR Average for Both

Examiners . . . . . . . . . . . . 19

IV Number of Child's Responses Compared with MLR.

for Each Examiner . . . . . . . . . 23

V Socio-Economic Ranking of Subjects . . . . . . . 27 


\section{LIST OF FIGURES}

FIGURE

PAGE

1 A Comparison of the MLR of Each Subject When

Examined by the Mother and the Speech

Pathologist . . . . . . . . . . . 17

2 A Comparison of MLR Achieved by Each Subject in

the First and Second Examination Without Regard

to the Examiner . . . . . . . . . 20 


\section{CHAPTER I}

\section{REVIEW OF THE LITERATURE AND STATEMENT OF THE PROBLEM}

\section{INTRODUCTION}

The study of child development has led to the study of normal language acquisition. The child's abilities to understand and be understood are used as indications of his overall level of development (McCarthy, 1954). The importance of knowing the developmental stages of normal language acquisition has led investigators to establish standardized methods of measuring language development (McCarthy, 1930; Dávis, 1937: Templin, 1957; Winitz, 1959; Cowan, et al., 1967). Language evaluations usually occur in either a clinic or in a public school. Factors may be present in the setting that affect the larguage evaluation. Removal of the child from faniliar surioundings may affect the quality or quantity of his language. As a consequence, an inaccurate picture of the child's speech and language abilities may be established (McCarthy, 1930; Davis, 1937; Van Riper, 1963). For this reason, the speech pathologist asks the parents to describe the speech ard language behavior of the child outside the evaluation seting. In order to establish an adequate picture of the child's linguistic abilities, various interview and questionnaire techniques have been developed as methods of determining the amount of language and vocabulary the child uses in his normal environment, ard to discover any facets of his language not observed during an evaluation. 
In the past, investigators have assumed that a child's linguistic abilities wili differ when he is confronted with an unfamiliar setting and examiner (Casteel, 1969). A further assumption is that a faulty assessment of speech and language will result. If these assumptions are true, the diagnos is and consequent plans for remediation will be based on incomplete or inaccurate information.

\section{REVIEW OF THE LITERATURE}

Research in the area of language acquisition has progressed from the observations of individual cases, such as those in the 18 th and 19 th centuries, to the current studies on the language behavior of groups of children. Where the early investigators kept records of a child's increasing vocabulary, contemporary investigatcrs have now designed more scientific methods of measuring numerous differentiated language characteristics. Out of this area of research, methods of quantitatively and qualitatively measuring language development have been devised (McCarthy, 1930; Davis, 1937; Templin, 1957; Winitz, 1959;

Cowar, et al., 1967). Investigators have been interested in such diverse parameters of language as onset of the first words (McCarthy, 195'), order and rate of appearance of speech sounds (Schneiderman, 1955; Templin, 1957), language patterns and psycholinguistic abilities (Gerber and Hertel, 1969), content and form of speech (Hahn, 1948), and amount and rate of speech (Smith, 1926; Mccarthy, 1930; Winitz, 1959; Striner and Sherman, 1967). The various measures have included rating of egocentricity (McCarthy, 1930; Davis, 1937), language structure and sentence complexity (McCarthy, 1930; Winitz, 1959; Minifie, 
et al., 1963; Shriner, 1969), vocabulary (Dunn, 1959; Smith, 1926), and length of response (McCarthy, 1930; Templin, 1957; Winitz, 1959).

The variety of language characteristics studied and the different methods used in those studies have made the comparison of the compiled data nearly impossible. For that reason, a standard technique of gatheririg data and method of analyzing it must be app!ied.

One index of lariguage development which is most frequently used, both alone and in conjunction with other language characteristics, is mean length of response (MLR). This particular dimension is within the realm of language expression. Mean length of response is defined as a measure of the average number of words per remark spoken in 50 responses. McCarchy (1930) eicited 60 responses, el iminated the first ten responses and computed MLR from the remaining 50 responses. These responses are elicited in a free play or semi-structured test situation where the child is encouraged to talk about toys or pictures (Cowan, et al., 1967). Study of MLR began as early as 1925, when Nice (1925) reported the various stages of sentence formation. She suggested that laverage sentence length may weil prove to be the most important single criterion for judging a child's progress in the attainment of adult language." Smith (1926), in her analys is of the spontaneous conversations of 84 children, conciuded that "the most significant trend in the development of the sentence with the increase of age was an increasing tendency toward the lise of longer more complete sentences." McCartiny (1930) studied several measures of linguistic ability including length of response, and proportions of various parts of speech and concluded that MLR was the "simplest and 
most objective measure of the degree to which children combine words at various ages." McCarthy further stated that no measure "seems to have superceded the mean length of sentence for a reliable, easily determined, objective, quantitative, and essily understocd measure of linguistic maturity"' (195/).

In a study comparing psychological rating scale values and MLR, Shriner and sherman (1967) found a higher correlation between thase two than between any other predictor variable studied. The ir conclusion was that, ". . if a single measure is to be used for assessment of language development, this one (MLR) thus would appear to be the most useful among those studied." In a review of language research, Cowan, et al. (1967) pointed out

While it is evident in at least nine studies that MLR increases with age, and that there are small but consistent class differences in length of response, other subject variables have not shown such consistent or clearcut effects.

Shriner (1969) in a later article reported that

Until there is further improvement of the lengthcomplexity measure . . mean length of response is a satisfactory predictor of language for children who are approximately five years of age or younger.

The extensive use of and the frequent study of MLR in the evaluation of language development have led to the discovery of several shortcomings in the use of MLR. In order that the data gathered in this area be more reliable, these shortcomings must be dealt with. Winitz (1959) and Seigel (1962) suggested the utilization of typed transcripts from tape-recordings to overcome the inaccuracies or biases of handwritien records. Webster and Shelton (1964) state "unfortunately, the amount of time required to obtain and transcribe 
a speech sample of 50 utterances and to tabulate MLR limits the clinical use that is made of this measure." However time consuming this task may be, the resultant data is far more reliable than estimates of MLR. The results of a study of the abilities of parents and teachers to estimate MLR "'. . indicated that parents and teachers cannot accurately estimate measured MLR" (Webster and Shelton, 1964).

The size of the language sample has been considered a source of inaccuracy by many investigators (Nice, 1926; McCarthy, 1930; Darley and Moll, 1960; Johnson, et al:, 1963; Shriner, 1969). McCarthy (1930) gathered the first 60 responses, el iminated the first ten responses, counted the number of words and divided by 50. Darley and Moll (1960) and Shriner (1969) concluded that a sample of 50 responses would be adequate for most purposes; however, any increase in the number of responses above 50 would increase the reliability of the sample.

The setting for obtaining a representative sample of the child's language has been considered by many investigators (McCarthy, 1930; Davis, 1937; Templin, 1957; Winitz, 1959; Van Riper, 1963; Black, 1964; Cowan, et al., 1967; Casteel, 1969; Mathis, 1970). The assumption in the past has been that the most repiesentative language sample would be obtained from a child when he was in a fainiliar, non-threatening environment. For this reason, previous data was gathered either at home or at school (McCarthy, 1930; Davis, i937; Templiri, 1957; Winitz, 1959). Casteel (1969) studied the effect on MLR of testing in. a comfortable (home) setting as contrasted with a clinical setting and concluded that the results "indicated no main effect difference between settings." he did find that "when considering the interaction of 
examiner and setting there are significant differences in performance between familiar setting and clinical setting."

Examiner variability and its effect on MLR has been a little known area until recently. McGuigan (1963) suggested an interaction between the examiner and the independent variable, whereby, the variation in examiners becomes a stimulus object affecting the resultant data. McGuigan conciuded by suggesting that the examiner differences in eliciting MLR could be the result of variation of the manner in which the independent variable is administered and the dependent variable is recorded or a variation in personality characteristics. In a study by Cowan, et al. (1967), there was a significant difference between two examiners. The difference appeared to be in relation to the age and sex of the subject. They stated, however, that the effects of the examiners were undefined because of the differences in task presentation, recording method, and scoring habits. In analyzing the data obtained by different examiners (mother and speech pathologist) in different settings (home and clinic), Casteel (1969) reported his data indicated

The high MLR results were obtained in a preferred setting for both examiners. The examination of these data seems to point most strongly to the need for the adult to be confort. able in the setting. It would seem reasonable to conclude that, other things being equal, the best results on language assessment would be gained by the speech pathologist in the ciinic and the mother in the home.

Mathis (1970) compared MLR elicited by different examiners in their most comfortable setting; the speech pathologist in the clinic and the mother in the home. Although there was no statistically significant difference between examiners, the speech pathologist did 
elicit a higher MLR average than the mother. Mathis concluded that the speech pathologist in the clinic elicited as representative a language sample as the mother elicited in the home.

In order for a speech pathologist to determine a child's leve!

of language development, he must gather a sample of language that is representative of the child's abilities. A language sample can be affected by many variables, including examiner variability. The speech pathologist should understand the effect this has on the language of the child being evaluated.

\section{PURPOSE OF THE STUDY}

The purpose of this study is to compare language samples elicited from children with normal language by two examiners in the same setting. The comparison will be between the verbal output of normal children observed in the clinic with the speech pathologist and the verbal output of the same children in the same setting with their mothers.

The primary question is: Does verbal cutput remain the same, regardless of the examiner?

Secondary questions are as follows: Does a neutrai seiting to both examiners, the speech pathologist and the mother, favor one type of examiner?

Does verbal output remain the same, regardless of the examiner, across a socio-economic spectrum?

Do racial differences affect the verbal output of children being examined by mothers and the speech pathologist? 
CHAPTER $\mid$ ।

\section{METHODS AND PROCEDURES}

\section{PROCEDURES}

The procedures that follow were used to gather language samples from which MLR scores could be computed. (1) Seven children were tested first by the mother in the test room and second by the speech pathologist in the test room. (2) Seven children were tested first by the speech pathologist in the test room and second by the mother in the test room. (3) A minimum of six days and no more than seven days elapsed between the first and second test situation. (4) The speech pathologist and the mothers were given typed instructions (Appendix 1) which described their task during the examination. The examiners were encouraged to ask any questions they might have regarding their responsibilities in the test situation, and the materials provided for gathering a ianguage sample. (5) Four of the 28 language samples were recorded on a UHER Universal Model 5000 tape recorder using a lavaiiere microphone on the subjects. Twenty-four of the 28 language samples were recorded on a Sony-Matic Model TC-104A tape recorder using a table microphone. (6) The tape recording of each language sample was mace into a typewritten transcript by a typist and the investigator. Both the typist and the investigator had been previously trained to perform this task (Appendix 11). (7) The resultant data was analyzed 
for MLR. This data was then analyzed statisticaily using the parametric t-test to determine if a significant difference existed between the MLR elicited by tha speech pathologist and the MLR elicited by the mother. This test was also used to determine the significance of racial differences, socio-economic differences, and the importance of order effect on the data.

\section{SUBJECTS}

Fourteen subjects with normal speech and language, nine males and five females, were chosen from the Greater Portland Area, Portland, Oregon. The mean age for this group of children was four years; the ages ranged from three years ten months to four years two months. There were no reported hearing losses, no physical handicaps, and none of the children were products of a multiple birth.

Although each child was to serve as his own control, the possibility of bias from a high socio-economic population could affect the data gathered. In an effort to attain a wide socio-economic scatter, seven of the children were selected from the Head Start pre-school program in Portland, Oregon. The remaining seven children were selected from co-operative pre-schools in the Greater Portland Area. To determine if a wide socio-economic scattering had been achieved, CURRENT POPULATION REPORTS: Consumer Income (1971) was utilized. The subjects' farilies were rated on the bas is of age, education, and income of the head of the household. In a study by Hegrenes (1970), aspects of social effectiveness were used including level of education and amount of incone. He stated that these aspects were scaled higher because of 
their emphasis in the American culture. Amount of education of the head of the household ranged from completion of the eleventh grade to completion of nine years of college. Incomes ranged from an annual income of $\$ 4,500$ to $\$ 25,000$. The resultant percentages were computed based on the entire U. S. population. The percentages for the study ranged from 6.3 percent to 99.8 percent. It was assumed that a wide sociomecononic scattering had been achieved.

The screening procedure established by Mathis (1970) was utilized in this study. Each child was screened prior to the examination dates. The screening procedure consisted of the utilization of the CCD Language Manual, University of Oregon Medical School; the Peabody Picture Vocabulary Test; and items through the four year level from the Stanford Binet Intelligence Scale. Each child in the study was at age level on the CCD Language Marilial and scored a mental age of four years or higher on the Stanford Binet Intelligence Scale. The minimum. score allowed on the Peabody Picture Vocabulary Test was an intelligence quotient of 80 . All children exceeded this limit; scores ranged from 86 to 124 with a mean of 103 and a median of 104 .

\section{EXAMINERS}

Orie speech pathologist at the doctorate level and 14 mothers were the examiners. The examiners were provided with typed instructions at the time of the taping session (Appendix 1) which described the task required during the examination. No other instructions were given as to how to elicit spontaneous conversation. The investigator wanted each examiner to use her normal method to elicit responses from the 
child. Each examiner was allowed the opporiunity to examine the materials available to her for the taping session and ask questions for clarification.

\section{TEST SESSIONS}

Twenty-e ight 15-minute tape recordings of spontaneous conversa-tion between the speech pathologist and the children and the mothers and the children were obtained. Winitz (1959) initially studied the method of audio-tape recording language samples. This method was further studied by Darley and Moll (1960), Siegel (1962), Minifie, et al. (1963), and Webster and Shelton (1964). Siegel (1962) suggested the utilization of tape recordings to overcome the biases of handwritten records. Minifie, et al. (1963) reported that the discrepancies between tape recordings and longhand notes exist and are significant favoring tape recordings.

\section{SETTING}

For the purpose of determining the effect the examiner has in a test situation, the following proceduies were followed. Two examiners, the speech pathologist and the mother, conducted the examination in the same setting. The setting was the future speech therapy room for the Head. Start program, which at the time had not yet been used. Neither the mothers nor the speech pathologist had been in the room prior to the tape recording sessions. According to Casteel (1969), this would place the speech pathologist in her most comfortable setting, i.e. the clinic. Sy keeping the setting constant, the effect 
of the examiner in that setting on the child's language sample might be more clearly understood.

\section{TRANSCRIPTS}

Following the completion of the tape recordings, each 15-minute recording was made into a type-written transcript (Apperidix IV) by a typist and the investigator. These transcripts followed the pattern of McCarthy (1930), Templin (1957), Winitz (1959), Siegel (1962) Casteel (1959) and Mathis (1970). In order to increase the rei iability of the transcript, siegel (1962) suggested the typist be trained prior to typing the transcripts. Written instructions (Appendix 11) previously established by Casteel (1969) and Maihis (1970) were utilized in this study. The typist and the investigator were each trained on three 15-minute tape recorded language samples. The investigator was responsible for the corrections and the resultant fina! transcripts.

\section{MLR ANALYSIS}

Mean length of response was computed from each transcript for each child resulting in 28 MLR averages. The system followed was similar to the ones used by McCarthy (1930), Davis (1937), Templin (1957), and winitz (1959). These researchers divided the total number of words in a 50-response language sample by the total number of responses. They used a language sample based on 50 responses. In this study, the total number of words fer $15 \cdot$ minute session was divided by the total number of response units in that session. This 
was the method used by Casteel (1969) and Mathis (1970).

A 15 -ininute langliage sample was chosen because of findings by Webster and Shelton (1964), Casteel (1969), and Mathis (1970). Their research indicated that a $15-m i n u t e$ session would result in a language sample of sufficient size as to be deemed representative. The examiner then was not responsible for counting responses, and consequently was free to interact with the child.

\section{RELIABILITY}

The inter-judge reliability examination included two judges and the investigator. The two judges were acknowledged as having the necessary skills required for this task. One had been involved in two previous studies of this nature, the other was a member of the staf of the Speech and Hearing Sciences Department, Portland State University.

A training session was provided for the judges prior to the session for MLR analysis. Typed instructions (Appendix III) and six training samples were used for this training session. The six training samples were chosen to demonstrate the types of speech episodes that could occur during the MLR analysis session.

Fifty speech samples were then chosen at random from the 28 tapes. Each minute within the 15-minute session was listed. By using a random table, two of these minutes were chosen. Those were minute seven and minute ten of each tape recording. The first complete aduit-child response sequence following each of those minutes was used as a speech episode for the MLR analysis session. Mechanical difficulties with the tape recorders used to transfer the sample 
episodes from the original tape to the MLR analysis tape resulted in the necessity of el iminating six of the 56 speech samples. For this reason, there were only 50 speech samples for the MLR analys is session. These 50 speech episodes were then presented to the judges for MLR analysis. Of these 50 speech samples, 11 were chosen at random and presented to test intra-judge reliability. Two judges demonstrated 100 percent agreement on the test-retest samples. The third judge demonstrated 91 percent agreement on the test-retest samples. Interjudge reliability was 88 percent for the three judges. The percentage of agreement between the investigator and each judge was higher (92 percent) than the percentage of agreement between the two judges ( 88 percent). The results of the reliability check indicated that the investigator's ability to analyze MLR was adequate.

\section{IX, DATA ANALYSIS}

The population for this study was chosen at random. The population was small and involved two independent samples. The data was quantitative in nature. For these reasons the parametric tatest was used for statistical treatment of the gathered data. This test was also used to examine racial differences, socio-economic differences, and the importance of order effect on the data. The Spearman Rank Correlation Coefficierit was used to determine the consistency of each subject's performance when compared to that of his peers. 
CHAPTER $\mid$ ।

RESULTS AND DISCUSSION

\section{RESULTS}

Mean length of response (MLR) analysis was performed on transcripts from the 28 fifteen-minute examinations conducted by the speech pathologist and the mothers in the clinic (Table 1). This data was then subjected to statistical analysis by means of the parametric t-test for significance.

in the examinations performed by the speech pathologist, MLR ranged from 1.80 to 5.22 for the 14 subjects with the average being 3.78 (Figure 1). In the examinations performed by the mothers, MLR ranged from 2.35 to 4.47 for the 14 subjects with the average being 3.20 (Figure 1). Statistical analysis of this difference by means of the $t$-test showed a significant difference between the examiners at the .05 level of confidence in favor of the speech pathologist. The presentation of statistical results are found in Table 11 .

Combining the 28 examinations without respect to the examiner revealed an MLR average of 3.49 with a range among the individual subjects of 1.80 to 5.22 . The combined MLR average of 3.49 for this study, the MLR average of 3.20 achieved in the mothers' examinations and the MLR average of 3.78 achieved in the speech pathologist's examinations were all below the rorms established by previous researchers 
TABLE

MLR OBTAINED BY EACH EXAMINER AND DIFFERENCES

IND IVIDUALLLY AND COLLECTIVELY

\begin{tabular}{|c|c|c|c|}
\hline \multirow[b]{2}{*}{ Subject } & \multicolumn{2}{|c|}{ Examiner } & \multirow[b]{2}{*}{ di } \\
\hline & $\begin{array}{c}\text { Speech } \\
\text { Pathologist }\end{array}$ & Mother & \\
\hline $\begin{array}{r}1 \\
2 \\
3 \\
4 \\
5 \\
6 \\
7 \\
8 \\
9 \\
10 \\
11 \\
12 \\
13 \\
14\end{array}$ & $\begin{array}{l}3.92 \\
4.58 \\
3.53 \\
3.54 \\
2.28 \\
3.97 \\
3.21 \\
4.58 \\
3.56 \\
3.74 \\
4.41 \\
1.80 \\
5.22 \\
4.58\end{array}$ & $\begin{array}{l}2.69 \\
3.83 \\
2.93 \\
3.14 \\
2.35 \\
3.01 \\
3.04 \\
3.41 \\
2.87 \\
2.78 \\
3.99 \\
2.74 \\
4.47 \\
3.56\end{array}$ & $\begin{array}{r}1.23 \\
0.75 \\
0.60 \\
0.40 \\
-0.07 \\
0.96 \\
0.17 \\
1.17 \\
0.69 \\
0.96 \\
0.42 \\
-0.94 \\
0.75 \\
1.02\end{array}$ \\
\hline Total & 52.92 & 44.81 & 8.11 \\
\hline $\bar{x}$ & 3.78 & 3.20 & 0.579 \\
\hline
\end{tabular}

for the normal population. The McCarthy (1930) norms indicate a MLR average of 4.4 for the four-year-old child and the Templin (1957) norms indicate a MLR average of 5.4 for the four-year-old child. The combined iLR average for this study was .91 below the McCarthy norms and 1.91 below the Templin norms. The MLR resulis from the mothers' examinations were 1.20 below the McCarthy norms and 2.20 below the Templin norms. The MLR results from the speech pathologist's examinations were .62 below the McCarthy norms and 1.62 below the Templ in norms.

When the scores from both examinations were analyzed with regard to the sex of the chiid, the MLR averages were 3.41 for boys and 3.70 


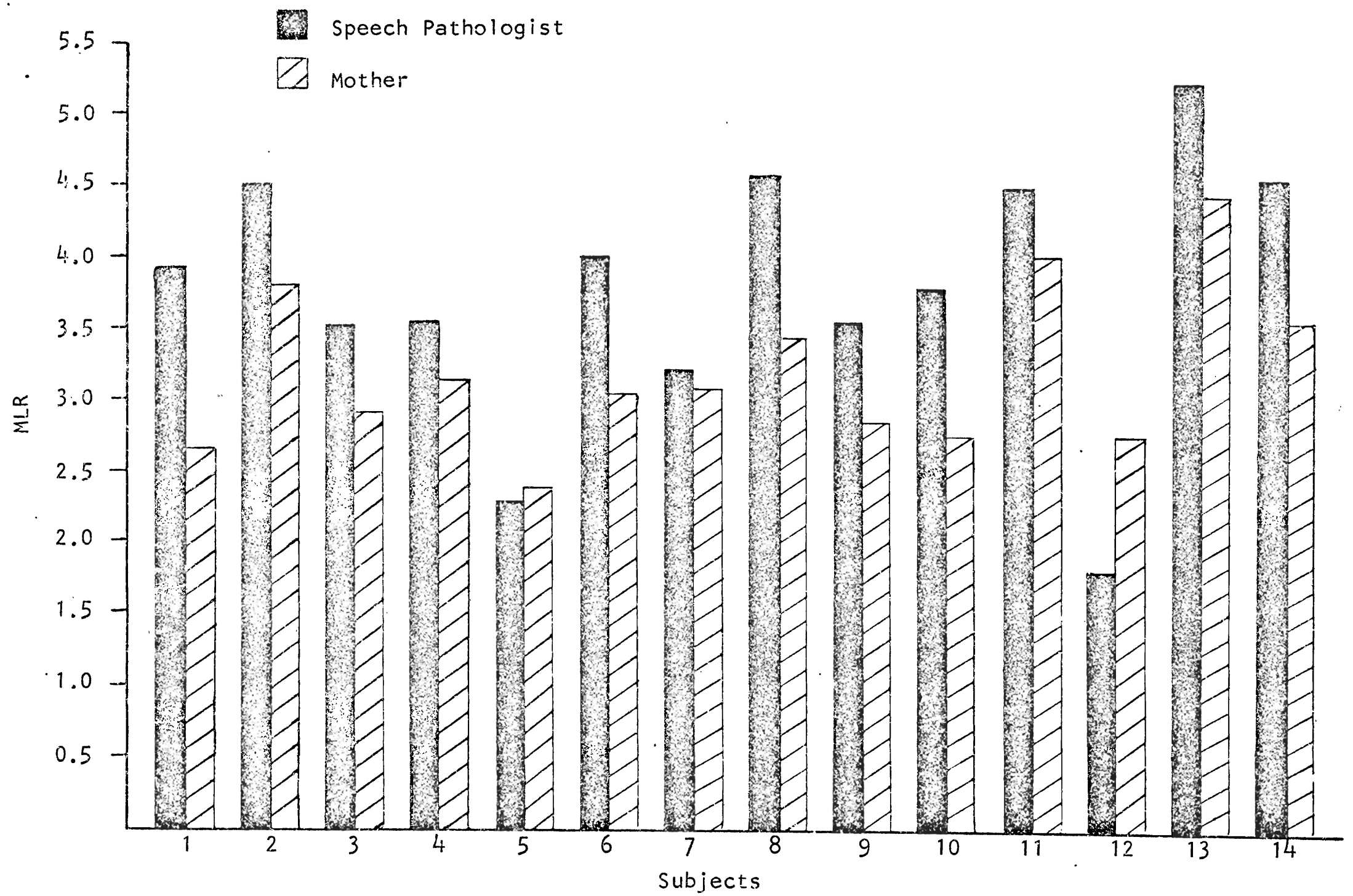

Figure 1. A comparison of the MLR of each subject when examined by the mother and the speech pathologist. 
TABLE ! ।

T-PATIO WHEN COMPARING MLR OF CHILDREN EXAMINED
BY SPEECH PATHOLOGIST AND MOTHER, BLACK
CHILDREN AND WHITE CHILDREN, HIGH AND
LOW SOCIO-ECONCMIC GROUFS, AND
FIRST AND SECOND EXAMINATION

\begin{tabular}{|c|c|c|c|}
\hline COMPARISON & N & d.f. & $\mathrm{t}$ \\
\hline $\begin{array}{l}\text { Mother Us. } \\
\text { Speech Pathologist } \\
\text { Black Children Vs. } \\
\text { White Children } \\
\text { High Socio-economic Vs. } \\
\text { Low Socio-economic } \\
\text { 1st Examination Vs. } \\
\text { 2nd Examination }\end{array}$ & $\begin{array}{l}28 \\
28 \\
28\end{array}$ & $\begin{array}{l}26 \\
26\end{array}$ & $\begin{array}{l}2.29 * \\
1.58 \\
.312 \\
2.025\end{array}$ \\
\hline
\end{tabular}

$*<.05$ Level of Confidence

for girls. This was analyzed further with regard to each examiner. The MLR average of the girls with mothers was 3.24. The MLR average of boys with mothers was 3.19. The MLR average of girls with speech pathologist was. 4.16. The MLR average of boys with speech pathologist was 3.63 .

When the scores from both examinations were analyzed with regard to racial differences of the children, the MLR average for black children was 3.31 and the MLR average for white children was 3.62 . Statistical analysis of this difference by means of the $t$-test shows no significant difference at the .05 level of confidence. There was, however, a trend for the white children to have a longer MLR average than the black children.

The 14 subjects were divided into two groups depending upon the age, education, and income of the head of the household. The scores of 
these two groups from both examinations were analyzed to determine if a difference existed between the socio-economic groups in this study. The parametric t-test was used and there was no significant difference at the .05 level of confidence.

As indicated in Figure 2, MLR was analyzed according to the order of examination. Without respect to examiner, the MLR average for the first examination was 3.45. The MLR average for the second examination was 3.53 . Using the t-test, no significant difference was found at the .05 level of confidence.

The $M ! R$ averages were separated into two groups, depending upon who the examiner was during the examination. These MLR averages were then ranked within the two groups (Table 111 ). The Spearman Rank

TABLE II I

SUBJECTS RANKED BY MLR AVERAGE FOR BOTH EXAM!NERS

\begin{tabular}{|c|c|c|c|c|c|}
\hline \multirow[b]{2}{*}{ Subject } & \multirow[b]{2}{*}{ Rank } & \multicolumn{2}{|c|}{ Examiner } & \multirow[b]{2}{*}{ Rank } & \multirow[b]{2}{*}{ Subject } \\
\hline & & $\begin{array}{c}\text { Speech } \\
\text { Pathologist }\end{array}$ & Mother & & \\
\hline 13 & $1 \mathrm{st}$ & 5.22 & 4.47 & $1 \mathrm{st}$ & 13 \\
\hline 2 & $3 \mathrm{rd}$ & 4.58 & 3.99 & 2 nd & 11 \\
\hline 8 & $3 \mathrm{rd}$ & 4.58 & 3.83 & $3 \mathrm{rd}$ & 2 \\
\hline $1 t_{t}$ & $3 r d$ & 4.58 & 3.56 & $4 \mathrm{th}$ & 14 \\
\hline 11 & 5 th & 4.41 & 3.41 & 5 th & 8 \\
\hline 6 & 6 th & 3.97 & 3.14 & 6 th & 4 \\
\hline 1 & $7 \mathrm{th}$ & 3.92 & 3.04 & $7 \mathrm{th}$ & 7 \\
\hline 10 & Sith & 3.74 & 3.01 & 8 th & 6 \\
\hline 9 & 9th & 3.56 & 2.93 & $9 \mathrm{ch}$ & 3 \\
\hline 4 & $10 \mathrm{th}$ & 3.54 & 2.87 & 10 th & 9 \\
\hline 3 & 11 th & 3.53 & 2.78 & 11 th & 10 \\
\hline 7 & 12 th & $3.2 i$ & 2.74 & 12 th & 12 \\
\hline 5 & 13 th & 2.28 & 2.69 & $13 \mathrm{th}$ & 1 \\
\hline 12 & 14 th & 1.80 & 2.35 & $14 \mathrm{th}$ & 5 \\
\hline
\end{tabular}




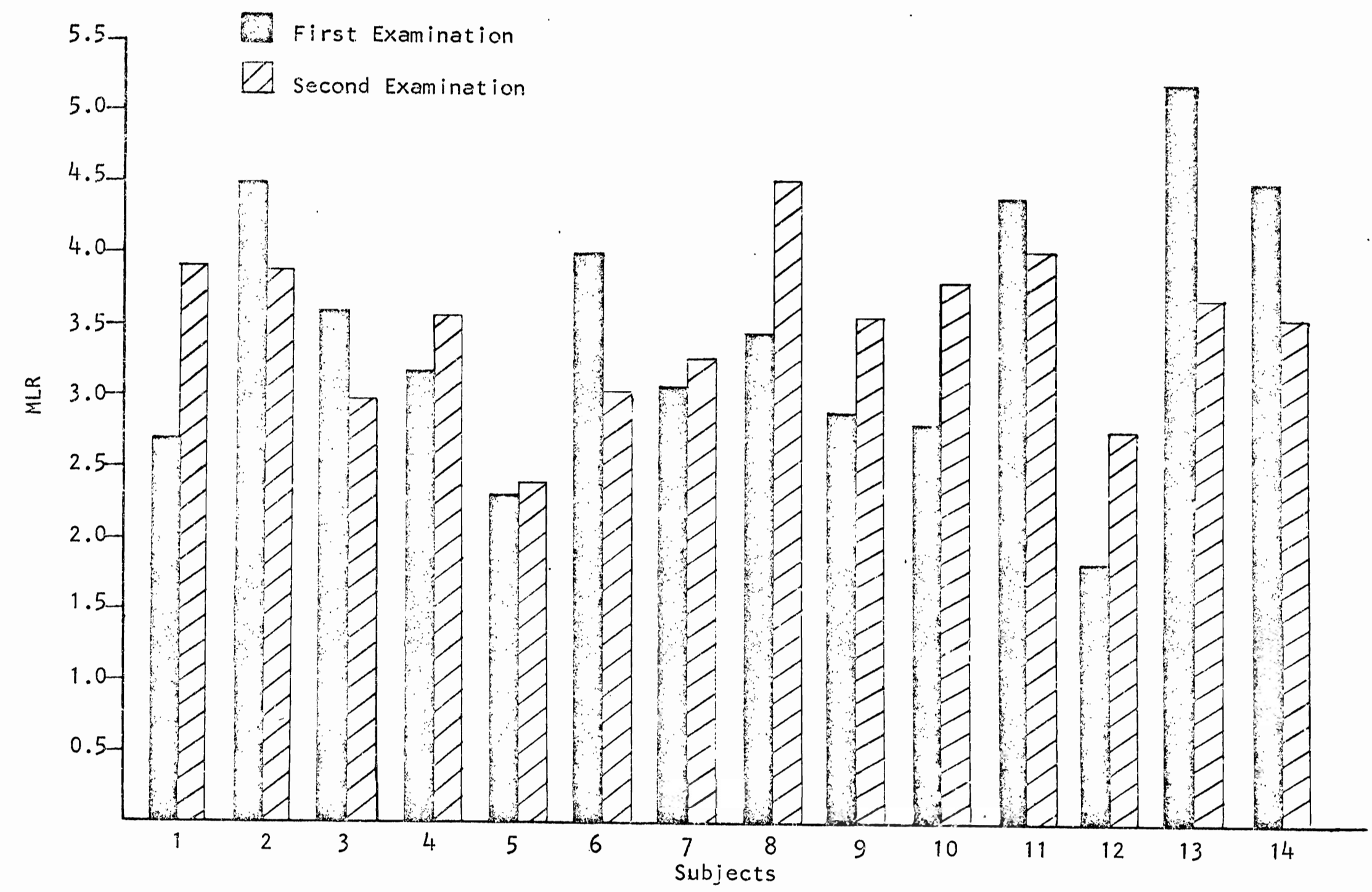

Figure 2. Comparison of MLR achieved in first and second examination regardless 
Correlation Coefficient test was used to determine the degree of association between the MLR achieved by the 14 subjects with the two examiners. The resultant coefficient was .741 , which when subjected to the $t$-test was significant at the .01 level of confidence.

\section{DISCUSSION}

The purpose of this study was to determine to what extent the MLR of children will differ when elicited by two examiners placed in the same setting. In this study, both examiners (the mothers and the speech pathologist) were placed in a neutral clinic setting.

Does Verbal Output Rema in The Same, Regardless of The Exaniiner?

The results cited in the previous section do indicate that the amount of language elicited, as measured by MLR, does change significantly for the sample tested. The amount of language (MLR) elicited by the speech pathologist in the test setting is greater than the MLR elicited by the mothers in the same setting. This tends to indicate that who the examiner is may be significant when attempts are made to estabiish language levels by this measure.

In the study by Casteel (1969), six children were examined by the speech pathologist in the home and in the clinic, and six children were examined by the mother in the home and in the clinic. Casteel concluded that ". . other things being equal, the best results on language assessment would be gained by the speech pathologist in the clinic and by the mother in the home." In a study by Mathis (1970), six children were examined by the speech pathologist in the clinic 
and the mother in the home. Five of the six children in her study

Produced comparable or better MLR in the clinic than they produced in the home. . . . This indicates a probability that the speech pathologist obtained a sample of the child's speech that is representative of the child's optimum speech output.

The results of the present study suggest that the speech pathologist does, in fact, elicit a language sample in the test setting that is more representative of the child's language capabilities than the language sample elicited by the mother in the same test setting, e.g. outside the home.

When looking at the MLR averages of each child, two children achieved a higher MLR with the mother than with the clinician. The differences between the two examinations were .07 and .94 in favor of the mother. In both cases, the mothers elicited more total responses from the child than did the speech pathologist (Table IV). The number of responses in the first case was 74 for the speech pathologist and 117 for the mother. In the second case, the speech pathologist elicited 93 responses and the mother elicited 184 responses. The number of responses elicited by the speech pathologist in both these cases meets the criteria of 50 responses needed for clinical purposes set by McCarthy (1930) and used by later researchers such as Templin (1957) and Shriner (1969). There has been some controversy, however, over the temporal reliability of a 50-response language sample. Historically. Nice (1925) suggested that in order for studies to be comparable, at least 100 responses vould be necessary, Minirie, et al. (1963) stated that lany single mean obtained from a 50-response language sample. . is only a gross estimate of the child's true Mean Length 
TABLE IV

NUMBER OF CHILD'S RESPONSES COMPARED WITH

MLR FOR EACH EXAMINER

\begin{tabular}{|c|r|c|c|c|}
\hline \multirow{2}{*}{ Subject } & \multicolumn{3}{|c|}{ Examiner } \\
\cline { 2 - 5 } & \multicolumn{2}{|c|}{$\begin{array}{c}\text { Speech } \\
\text { Pathologist }\end{array}$} & \multicolumn{2}{c|}{ Mother } \\
\hline & Responses & MLR & Responses & MLR \\
\hline 1 & 99 & 3.92 & 117 & 2.69 \\
2 & 167 & 4.58 & 180 & 3.83 \\
3 & 119 & 3.53 & 115 & 2.93 \\
4 & 65 & 3.54 & 126 & 3.14 \\
5 & 74 & 2.28 & 117 & 2.35 \\
6 & 105 & 3.97 & 187 & 3.01 \\
7 & 193 & 3.21 & 190 & 3.04 \\
8 & 149 & 4.58 & 149 & 3.41 \\
9 & 115 & 3.56 & 175 & 2.87 \\
10 & 160 & 3.74 & 197 & 2.78 \\
11 & 219 & 4.41 & 172 & 3.99 \\
12 & 98 & 1.80 & 184 & 2.74 \\
13 & 178 & 5.22 & 156 & 4.47 \\
14 & 128 & 4.58 & 135 & 3.56 \\
& & & & \\
\hline
\end{tabular}

of Response." They concluded that MLR did not appear to have a high temporal reliability when based on a 50-response language sample. The results of a study by Darley and Moll (1960) indicated that the reliability of MLR scores derived from 50-response language samples was "adequate for most purposes." They further stated that increasing the number of responses in the language sample would improve the reliability of the scores; however, for MLR "a fairly large increase would be required to improve reliability appreciably." They did not state how large an increase would be necessary. According to past research, this may have been a contributing factor resulting in the speech pathologist obtaining a lower MLR from those children than the mothers. There were seven other cases in which the speech pathologist elicited fewer total 
responses than the mother elicited. Of these seven, twice the speech pathologist elicited fewer than 100 total responses for that language sample. The speech pathologist, however, did obtain a significantiy higher MLR average from the children than did the mother. Number of resporises then may not be the oniy explanation for the speech pathologist eliciting a lower MLR average than the mothers in those two cases. When MLR per child was ranked from the lowest to the highest for each examiner (Table II!), it was observed that the two cases ir which the speech pathologist elicited a lower MLR average than the mother were at the low end of the continuem for both the speech pathologist and the mothers. These two cases were the lowest when the speech pathologist was the examiner and among the three lowest when the mothers were the examiners. It would appear then that these two children maintained a low verbal output regardless of the examiner. It should be noted here that this low verbal output vas also observed during the initial screening of subjects. During screening, both children appeared either unable or unwiliing to verbalize freely with the investigator. In the first case, the difference between the MLR obtained by the speech pathologist and the mother was .07 ; the two examiners obtained nearly equal MLR averages. This child verbalized nearly as freely with the speech pathologist as with the mother. In the second case, the difference between the MLR cbtained by the speech pathologist and the mother was .94; the child verbalized more freely with the mother than with the speech pathoiogist. It is possible that the term reticent speaker would apply to the second case. If so, this would partially expiain the lower MLR average elicited from this child by the speech 
pathoiogist. Other factors may be involved in these two cases which are not readily observable.

Regardless of other factors that might be involved in influencing the output differences (MLR) between examiners with a given child, the evidence points to relative consistency of the child's performance with that of his peers in the present study. The results of the Spearman Rank Correlation Coefficient (.741) indicate that when this group of children were seen by more than one examiner, each child achieved comparatively similar MLR results with both examiners. This seems to suggest that a child's performance will be consistent when compared to the performance of other children when both a speech pathologist and the child's mother examine the child in a clinical setting.

Does A Neutral Setting To Both Examiners, The Speech Pathologist And The Mothers, Favor One Type of Examiner?

The examination setting was the future speech therapy room for the Head Start program. It was not in use at the time of the taping sessicns. The term "neutral" is used here because prior to the taping sessions, rieither the speech pathologist nor the mothers had seen the room. The mothers each spent the time for one taping session in the examination room. The speech pathologist, however, spent the time for 14 tapirig sessions in the examination room. It would appear that the time spent in the setting would allow the speech pathologist to become more accustonied to the setting and, therefore, it would be a more comfortable setting for the speech pathologist. This was not considered to have a significant effect on the overall results of this study. The 
difference between the verbal output elicited by the speech pathologist and the mothers did not become increasingiy larger with each child seen by the speech pathologist. Rather, the difference between the output elicited by the speech pathologist and the mothers for the last seven children was less than the difference between the output elicited by the speech pathologist and the mothers for the first seven children. The time the speech pathologist spent in the examination room did not improve the speech pathologist's ability to elicit increasingly higher MLR averages from the children than that elicited by the mothers. The results of this study may indicate that the speech pathologist generalizes her most comfortable setting ( $c$ inic) to any clinical setting. The mother, on the other hand, may not generalize her most comfortable setting (home) to a neutral setting. According to Castee (1969), this would give the speech pathologist the advantage of being in her most comfortable setting, i.e. the clinic setting. It would appear then that the clinic. setting used in this study may, in fact, have favored the speech pathologist.

Do Racial Differences Affect The Verbal Output of Children Being Examined By The Mothers And The Speech Pathologist?

In comparing the MLR average of black children with the MLR average of white children, it was observed that the white children tended to have a longer MLR average than the black children. This difference, however, was computed slatistically by means of the $t$-test and wes found to be not significant at the .05 level of confidence. of the six black children in the study, three achieved fewer than 100 total responses when examined by the speech pathologist. 
In one case, the mother elicited a higher MLR average than did the speech pathologist.

Does Verbal Output Remain The Sarne, Regardless of The Examiner, Across A Socio-economic Spectrum?

The 14 subjects were divided into two groups on the basis of age, education and income of the head of the household. The dividing point was arbitrarily set at the 50 percent point, placing six subjects above this point and eight subjects below it (Table V). A wide socio-economic scatter was achieved in this study, ranging from 6.3 percent to 99.8 percent of the total U.S. population. The breakdown between the high and low group was not between subjects from the Head Start program and

TABLE V

SOCIO-ECONOMIC RANKING OF SUBJECTS

\begin{tabular}{|c|c|c|c|c|}
\hline \multirow{2}{*}{ Subject } & \multicolumn{2}{|c|}{ Head of Household } & \multirow{2}{*}{$\begin{array}{l}\text { Family } \\
\text { Income }\end{array}$} & \multirow{2}{*}{$\begin{array}{c}\text { Percentile } \\
\text { Ranking }\end{array}$} \\
\hline & Age & Education & & \\
\hline 1 & $25-34$ & Coll. 2 & $\$ 25,000$ & 99.8 \\
\hline 2 & $25-34$ & Coll. 4 & 15,000 & 95.5 \\
\hline 3 & $25-34$ & H.S. 3 & 10,800 & 84.0 \\
\hline 4 & $45-54$ & Coll. 1 & 18,000 & 71.0 \\
\hline 5 & $25-34$ & H.S. 4 & 11,000 & 70.3 \\
\hline 6 & $25-34$ & $\operatorname{Coll} \cdot 1 \frac{1}{2}$ & 10,000 & 58.7 \\
\hline 7 & $25-34$ & Coll. 4 & 10,000 & 43.2 \\
\hline 8 & $25-34$ & Col!. 9 & 11,500 & 39.5 \\
\hline 9 & $25-34$ & Coll. 6 & 10,000 & 39.5 \\
\hline 10 & $35-44$ & H.S. 3 & 6,300 & 27.2 \\
\hline 11 & $25-34$ & H.S. 4 & 5,000 & 24.7 \\
\hline 12 & $25-34$ & Coll. 2 & 6,000 & 15.0 \\
\hline 13 & $25-34$ & Coil. 1 & 5,500 & 10.0 \\
\hline 14 & $25-34$ & Coll. 1 & 4,500 & 6.3 \\
\hline
\end{tabular}


subjects from other preschoois. Three of the six subjects in the high socio-economic group were from the Head start program. Four of the subjects in the low socio-economic group were from preschools other than Head Start. The difference between the average MLR of the two groups was .47 , in favor of the low socio-economic group. This difference was analyzed statistically by means of the t-test and found to be not significant at the .05 level of confidence.

There does not appear to be a high correlation between the socioeconomic ranking of the subjects (Table $V$ ) and the ranking of MLR as elicited by the speech pathologist (Table III). Of the six subjects in the high socio-economic group, only one was among the highest six in the MLR ranking achieved when the subject was examined by the speech pathologist. That subject was ranked 5 th on both scales. The remaining five in the high socio-economic group were ranked between 8 th and 13 th in achieved MLR. The remaining top five in MIR ranking were in the low socio-economic group. It would appear that factors other than those used to rank the socio-economic status of the subject affect the MLR of the children.

Other Considerations

Order Effect. The first and second examinations were conpared to determine the effect of order on the examinations (Figure 2). Fourteen children were seen twice. Of these 14 children, six achieved a higher MLR on the first examination and eight achieved a higher MLR average on the second examination. The difference between the average MLR of the two groups was .08 . By means of the $t$-test, it was deternined that the order effect was not significant at the .05 level 
of confidence. There was, in fact, more agreement between the first and second examination than between the speech pathologist's and the mothers' examinations.

Contrasting MLR Results With Normative Data. When comparing the MLR average obtained in this study with the MLR norms established in previous studies, some obvious differences are noted. The 0.62 difference between the speech pathologist's examinations and the norms established by McCarthy (1930) for four-year-old children does not appear to be significant. The 1.62 difference between the speech pathologist's examinations and the norms for four-year-old children established by Templin (1957) does appear significant and warrants closer investigation. The 1.20 difference between the mothers' examinations and the McCarthy norms and the 2.20 difference between the mothers' examinations and the Templin norms are of a greater magnitude; however, they could be the result of examiner differences. In both the McCarthy and Templin studies, the examiners were trained and experienced in eliciting language samples. The mothers in this study were not trained in these techniques. The mothers in the study by Mathis (1970) were not trained in these techniques either. Mathis did not $f$ ind a statistically significant difference between the MLR of children examined by the speech pathologist in the clinic and the MLR of children examined by their mothers in the home. It is interesting to note, however, that the difference between her two groups was .58 and the difference between the two groups in this study was .58 . It is possible that the difference in the Mathis study may have been significant had she had a larger sample of subjects. 
Several factors have been suggested in previous research that could account for decreased MLR; however, norie of them appear to be applicable to this study. Davis (1937), arid Minifie, et al. (i963) have reported that twins will dispiay a reduced MLR. None of the subjects in this study were the product of a multiple birth. Smith (1939) suggested that those children from bilingual homes would display a reduced MLR. Miclarthy (1930), on the other hand, did not feel that chiláren from a home in which a foreign language was spoken would be seriously handicapped. No subjects in this study resided in bilingual homes. McCarthy (1930) and Winitz (1959) cited belcw average intelligence as having a possible correlation with reduced MLR. Intelligence measures employed for this study indicated that all children were of average or above avarage intelligence. Research done by various investigators including Smith (1926), McCarthy (1930), Davis (1937), Irwin (1948), Templ in (1957), Cowan, et al. (1967) and Gerber and Hertel (1969) has shown differences in language development between socio-economic groups, with iower socio-economic groups and disadvantaged children displaying reduced MLR. There was a wide sociomeconomic scatter in this study; however, when the subjects were separated into two groups, no significant difference between the achieved MLR of these two groups was demonstrated when analyzed statistically. This was based on the .05 leyel of confidence. Furthermore, there did not appear to be a high correlation between the amount of language (MLR) a child ernitted and his socioeconomic rating.

In view of these control and results, no valid conclusion can be drawn as to the reason for differences in MLR between this study 
and previous!y established norms. Consequently, it might be useful to examire the research data available on examiner differences.

The research in the area of examiner differences offers several reasons which could contribute to the differences between normative data and the results of this study. In a review of various studies, McGuigan (1963) suggested an interaction between the examiner and the independent variable of the experiment. The variations in the examiners becomes a stimulus object, thereby affecting the outcome of the experiment. One study that McGuigan reviewed involved the interaction of subject and examiner characteristics. In another study, nine examiners replicated a single experiment. Not only were there various degrees of difference, but contradictions in the results also occurred. McGuigan suggested variations in administering the independent variable and different personality characteristics as reasons for examiner differences. He further suggested further study in this area with better controls established between studies.

Minifie, et al. (1963) suggested that differences in recording techniques and environmental influences may account for discrepancies between studies. They suggest that comparison between studies would be of little value if previous norms were obsolete. Further, tape recordings were used in this study, which differs from the handwritten records used by McCarthy and Templin.

Cowan, et al. (1967) suggested that stimulus and examiner variables could account for the differences in MLR obtained in different studies. The results of his study were affected by the examiner in relation to the age and sex of the subjests. This would not appear 
applicable to this study; all chiidren were the same age and the speech pathologist elicited a higher MLR average from both boys and girls than the mother elicited.

Wilson (1969) suggested that the method of eliciting a language sample was standard neither in regard to examiners and subject nor to a set of stimulus materials making the use of the McCarthy and Templin norms questionable. Certainly this objection would be true of any study following the McCarthy methodology.

The results of a study by Casteel (1969) indicated that the best results were obtained when the examiner was placed in his most comfortable setting. This factor was not accounted for in previous research. in this study, the speech pathologist was possibly in a more comfortable setting than the mothers, which would account for the statistical difference within this study, but would not accourit for the difference between the results in this study and the normative data.

Comparing and contrasting the MLR data in this study with the normative data is interesting, but it is not critical to the results of this study, for each subject acted as his own control. The primary comparison was between the two examiners with the same child. The research above indicates that examiners differ greatly in skill, proficiency, comfort in the test setting, personal characteristics, and their interaction with various characteristics of the subject such as age and sex. These factors, and others not so readily observable, may well have contributed to the differences between the results of this study and the normative data. 
In conclusion, there was a significant difference in verbal output elicited by different examiners in favor of the speech pathologist. The girls in this study achieved a higher MLR average than did the boys. When the children were grouped according to racial background, there was no significant difference in MLR between black children and white children. There was no significant difference in MLR when comparing the groups socio-economically. There was no significant difference in the amount of verbal output between the first and second examination. The MLR averages of this study were considerably lower than the previously established norms and the differences could be a result of one or several factors which were not established in this study and remain unidentified at this time. 
CHAPTER IV

SUMMARY, CONCLUSIONS AND IMPLICATIGNS

\section{SUMMARY}

One of the primary responsibilities of a speech pathologist is the assessment of a child's language. Many studies have been done in the area of language development. The results of these studies have varied causing concern among researchers over the validity of the data that has been gathered. Many factors that could affect the results of previous research have been investigated. The normative data on MLR was established by McCarthy (1930) and later revised by Templin (1957). Several factors involving the subjects which could affect the resuits of studies using MLR as a means of measuring language have been investigated. These factors include the presence of bilingualism in the home (McCarthy, 1930; Smith, 1926); the intelligence of the child (Mc.Carthy, 1930; Winitz, 1959); the socio-economic status of the family (Smith, 1926; McCarthy, 1930; Davis, 1937; Irwin, 1948; Templin, 1957; Cowan, et al., 1967; Gerber and Hertel, 1969); and whether the child was a product of a multiple birth (Davis, 1937; Minifie, et al., 1963). Until recentiy, there has been relatively little research about the effect of examiner differences on the results of language assessments. Research in the area of examiner differences has resulted in the discovery of factors which could affect the resulits of language 
assessments and, more specificaliy, MLR. Mcáuigan (1963) suggested the interaction of the examiner's personality characteristics and the independent variable. Cowan, et al., (1953) suggested examiner and stimulus variables could affect the subject according to the age and sex of the child. Wilson (1969) stated that there was no standardization for an examiner's method of eliciting a language sample or for the stimulus materials used by the examiner. Casteel (1969) suggested an interaction between the examiner and the setting of the examination. He concluded that the best results were obtained when the examiner was in his most comfortable setting (the mother in the home and the speech pathologist in the $\mathrm{clinic})$. In a study by Mathis (1970), the results of the Casteel study were substantiated. Mathis concluded that the speech pathologist elicits as representative a language sample from the child in the clinic as the mother elicits from the child in the home.

The purpose of this study was to discover to what extent the MLR of chiidren will differ when elicited by two examiners, the speech pathologist and the mother, who are in the clinical setting.

Fourteen children, four years of age, were examined in the clinical setting by the speech pathologist and the mother. Twentyeight 15-minute tape recorded conversations were transcribed, the MLR tabulated and the results were analyzed statistically by means of the t-test for significance. The Spearman Rank Correlation Coefficient was used to compare the consistency of each child's performance with that of his peers from one examination to another. 
The results indicate that there is a statistically significant difference between the amount of language elicited by the speech pathologist and the mother in favor of the speech pathologist when the examination takes place in the clinical setting. The .05 level of confidence was established for this test.

When the MLR average of the black children was compared to the MLR average of the white chiidren, the difference between the two groups was not found to be significant at the .05 level of confidence. There was a trend, however, for the white children to display a higher MLR average than the black children. The comparison of MLR averages between the two socio-economic groups in this study resulted in a difference that was not significant at the .05 level of confidence. When MLR was analyzed according to the order of examination, there was no significant difference between the first and second examination. The girls in this study achieved a higher MLR average than that achieved by the boys in this study. The results of this study aiso indicated that a child's performance will be consistent when compared to the perfornance of other children when both the speech pathologist and the mother examine the child in the clinical setting. The MLR averages of this study were lower than the normative data. The differences could be a result of factors not identified at this time.

\section{CONCLUS!ONS}

The findings in this study substantiate the results of the studies by Casteel (1969) and Mathis (1970). Higher MLR averages result when the examiner is in his most comfortable setting. In this 
case, the speech pathologist was in her most comfortable setting (the clinic) while the mother was outside her most confortabie setting (the home). The results of this study also indicate that the speech pathologist elicits a more representative language sample from the child in the clinic setting than does the mother in the same setting.

The results obtained in the rirst examinatior dici rot change significantly in the second examination. This was also true in the studies by Casteel and Mathis. These findings should alleviate concern about the use of one examination for an adequate or valid language assessment. Further, it should indicate that the use of one 15-minute taped dialogue may be used to establish an accurate MLR average for a child.

Tape recording a child's dialogue and transcribing it for analysis would prove too time consuming for routine slinical use. It would, however, be helpful when clinical findings are questionable, or to demonstrate growth following treatment since accountability is currently being stressed in speech pathology.

\section{IMPLICATIONS FOR FUTURE RESEARCH}

In fucure studies concerning MLR, it may be useful to discover those factors involved in socio-economic status that affect verbai cutput, if in fact they do exist, and study their relationship to language development. It is further suggested for future research that variables such as age, intelligence, and socio-economic status be matched with those used in establishing normative data to allow for comparison with the normative data. 
The importance of examiner differences, in regard to language assessments and the reliability of normative data, cannot be stressed too strongly. One study that would be especially relevant would be the comparison of the amounts of language elicited by different speech pathologists in the clinic seting. Two other studies that could be helpful in the area of examiner differences would be the comparison of amounts of language elicited by male and female speech pathologists, and a study of the types of examiner responses which elicit greater verbal output in children. These studies would be valuable to both speech and hearing training centers and service agencies. 


\section{A SELECTED BIBL IOGRAPHY}

Black, M. E., Speech Correction in the Schools. Englewood Cliffs, N.J.: Prentice-Hall, Inc. (1964).

Casteel, R.L., Comparison of amounts and types of comrnunication used by language delayed children in home and clinic. Unpublished Doctoral dissertation, University of Oregon (1969).

Cowan, P.A., J. Weber, B.A. Hoddinott, and J. Klein, Mean length of spoken response as a function of stimulus, experimenter, and subject. Child Developm., 18, 19!-203 (1967).

Current Population Reports, U.S. Bureau of the Census. Series P-60, No. 80, Income in 1970 of families and persons in the United States. Washington, D.C.: U.S. Government Printing Office (1971).

Darley, F.L., and K.L. Moll, Reliability of language measures and size of language sample. j. Speech Heaiting Res., 3, 166-173 (1960).

Davis, E.A., The development of linguistic skill in twins, singletons with siblings and only children from age five to ten years. Univ. of Minn. Child Welf. Monograph, 14 (1937).

Dewey, E., Infant Behavior. New York: Columbia University Press (1935).

Dunn, L..H., Peabody Picture Vocabulary Test. Minneapoi is, Minn.: American Guidance Service, Inc. (1959).

Gerber, S.E., and C, G. Hertel, Language deficiency of disadvantaged children. J. Speech Hearing Res., 12, 270-280 (1969).

Hahn, E., Analysis of the content and form of the speech of first grade children. Quarterly J. of Speech, 34, 361-366 (1948).

Hegrenes, J.R., The competence of persons institutionalized during infancy. Unpublished Doctoral dissertation, University of Chicago (1970).

Manual for Evaluation of Speech, Language and Hearing Development in Children, University of Oregon Medical School, Crippled Children's Division, n.p.: n.d. 
Mathis, J., Comparison of amounts of verbal response elicited by a speech pathologist in the clinic and a mother in the home. Unpublished Masters thesis, Portiand State University (1970).

McCarthy, D.A., Language development in chiidren. Chap. 9 in L. Carmichael (Ed.), Manual of Child Psychology. New York: Wiley (1954).

McCarthy, D.A., The langliage development of the preschool child. Inst. Child Welfare, Monograph Series, Number 4, Minneapol is: University of Minnesota Press (1930).

McGuigan, F.J., The experimenter: a neglected stimulus object. Psychological Bullet in, 60, $421-428$ (1963).

Nice, M.M., Length of sentences as a criterion of a child's progress in speech. J. of Educational Psychology, 16, 370-379 (1925).

Schneiderman, M., A study of the relationship between articulatory ability and language ability. J: Speech Hearing Dis., 20, 359364 (1955).

Shriner, T.H., A comparison of selected measures with psychological scale values of language development. J. Speech Hearing Res., $10,828-835$ (1967).

Shriner, T.H., A review of mean length of response as a measure of expressive language development in children. J. Speech Hearing Res. : 34, 61-68 (1969).

Shriner, T.H., and D. Sherman, An equation for assessing language development. J. Speech Hearing Res:, 10, 41-48 (1967).

Siegel, G.M., Verbal behavior of retarded children assembled with pre-instructed adults. J. Speech Hearing Dis., 20, 359-364 (1955).

Siegel, S., Non-Parametric Statistics for Behavioral Sciences. New York: McGraw-Hill Book Co (1956).

Smith, M.E., An investigation of the development of the sentence and the extent of vocabulary in young children. Univ. of lowa Stud. child Welf., 3, No. 5 (1926).

Smith, M.E., Some light on the problem of biiingualism as found from a study of the progress in mastery of English among pre-school children of non-American ancestry in Hawai i. Genetic Psych: Monographs, $21,121-284$ (1939).

Templin, Mildred C., Certain language skills in children, the ir development and inter-relationsinips. inst. Child Welf. Monogr. Ser., No. 26.' Minneafolis: Univ. Minn. Press (1957). 
Van Riper, C., Speech Correction: Principles and Methods. (Rev. 4th Ed.). Englewood Cliffs, New Jersey: Prentice-Hall (1963).

Webster, M.J., and R. L. Shelton, Estimation of mean length of response in children of normal and below average intellectual capacity. J. Speech Hearing Res., 7, 101-102 (1964).

Wilson, M.E., A standardized method for obtaining a spoken language sample. J. Speech Hearing Res., 12, 95-102 (1969).

Winitz, H., language skills of male and female kindergarten children. J. Speech Hearing Res., 2, 377-386 (1959).

Zelditch, M., A Basic Course in Sociological Statistics. New York: Hol.t, Rhinehart \& Winston (1959). 


\section{APPENDIX A}

\section{EXAMINER INSTRUCTIONS}

We are interested in obtaining a free sample of speech in a non-test situation. It is important that you feel free to get your child to talk by any means that you choose to use, for we want to obtain the greatest amount of talking from your child. There will be some things that you will have available to use, such as picture books and some toys which are generally of interest to young children. You may or may not want to use these books and toys. The important thing is to get as much "talk" from the child as possible.

We are aware that even children who are not thought to be shy of ten need encouragement before they talk freely to an adult. Anything you can do to increase the child's talking is to be encouraged. Think of your job as one of getting the child to give the best sample of his ability to communicate his ideas and thoughts. Hopefully, with the direct attention that you are paying to the child, he will talk to the best of his ability. This may mean that an extremely shy child won't talk as much, but he will talk as well as he can.

Finally, the only things you must do are to keep the child in the room for 15 minutes, and keep the child talking as much as possible during that time.

task?

Do you have any questions about what you are to do in the 


\section{APPENDIX B}

\section{TRANSCRIPT TYPIST INSTRUCTIONS}

In a speech situation betweeri an adult and a child, tape recordings have been made. These tape recordings are the only information we have regarding the conversation taking place between these two people; so, for this reason, it is critical that the typing be accurate. There are certain general and specific instructions that you need to adhere to at all times in transcribing these tape recordings.

A. General Instructions

1. Use the letter $A$ to designate utterances by the adult and use the letier $C$ to designate a response by the child.

2. Do not use standard punctuation, other than apostrophes, which are to be used to indicate the possessive case or contractions.

3. Any response or part of response, i.e., episode, which you canrot comprehend after diligent effort to determine what is being said, omit that entire episode from the transcript, even one word in an otherwise intelligible response. Since the language of children is not predictable by adult standards, one should not over rely on context clues for unclear or missing words. Many factors may contribute to the utterance being unintelligible: too low an intensity of utterance, environmental noise, speech defect, two people talking at once, or the recorder is malfunctioning. Do note that an unintelligible episode has occurred.

4. The speech response need not be a complete thought; but, if all words are intelligible, include the response. as one episode.

5. At times, you will find both the adult and the child talking at the same time. First type the complete response of the person interrupted and, then, type the other speaker's utterance.

6. Certain utterances are not meaningful words, but are vocal pauses, such as er, ah, andah, um, etc. Do not type vocal pauses.

7. Some words acoustically similar to meaningless interjections are considered as real words and should be typed, such as huh-uh, uh-huh, hm, or animal sounds which are used $\overline{i n} \mid \overline{i e u}$ of the name of the animal in a thought. An example would be, "The grrr is after the 
boy." Another example of a noise being an integral part of the response would be, "The cat goes meow."

8. Word and phrasai repetitions are excluded if they represent natural non-fluencies as opposed to repeating for stress or elaboration. An example would be: "He he he went home." The underlined woras in this example would not be typed.

B. Determining and Designating a Vocal Response Unit

1. Usually, a vocal response unit is ended by a complete stop for breath.

2. At times, it is indicated by a falling inflection.

3. At other times, it is indicated by a rising inflection, such as a question or exclamation.

4. At times, you may be able to recognize that one speech episode is complete when one person stops talking and the other person begins.

5. A vocal response unit may be the utterance of a single word, such as uh-huh, if it is an affirmation, huh-uh for negation, huh for interrogation or oh for exclamation.

6. A single word response that is not recognizable as a word or a word approximation is considered not to be a vocal response unit and should not be transcribed. As an example, if the response to the phrase, "The flag is red, white, and. . " was "dom," this would not be considered a vocal response; however, if the response was "boo," it is conceivable that this is a verbal approximation of "blue."

7. When one simple sentence is followed immediately by another simple sentence with no pause for breath, the two are considered to comprise one sentence if the second sentence is clearly subordinate to the first. Examples: "I have a sister she's in the fourth grade" and "I see a car it's a Ford."

8. Remarks which appear to be clearly enumerative, if separated by pauses, are considered separate response units.

C. How to Mark the Transcript

1. Indicate the beginning word of any speech episode by underlining it; and make the appropriate ending response which is a single slash (/) for a statement and a double slash (//) for a question.

2. It is important that, even if the episode is composed of only one word, it must be underlined and followed by the appropriate slash mark.

3. It is important to remember that each speaker must be designated appropriateiy and accurately.

D. Criteria for Counting Words

1. Contractions, whether those normally marked with an 
apostrophe (isn't) or assimilations (wanna) will be counted as two words.

2. All expressions of negation, of affirmation, or exclamation or of interrogation will be counted as one word. Exariples would be such expression as: uh-huh, oh-oh, or huh-uh.

3. Words that are compound nouns will be treated as one word, e.g., Bobbi Jo (one worc), Bobbi Jo English (two words). All hyphenated words will be treated as one word.

4. As in compound rouns under three above, slang expressions which appear as single units (my gosh) will be treated as one word.

5. All onomatopoet ic words (tweet-tweet) will be counted as one word. 
APPENDIX C

INSTRUCTIONS TO MLR JUDGES

\section{RULES}

Read attached instructions to typist.

\section{SUGGESTIONS.}

The transcript that you will be working with is far from infallible, even the recording rules are not always followed, to say nothing of judgmental differences. It is important that the basis for acceptance or rejection of a speech episode be the nervous system of the judge. It may be tempting to accept the transcript, especially if you agree with certain key words. Listen again to see if you can agree with all of the words in a long episode. Especially in long episodes it is tempting to accept the transcript without 1 istening to each word.

It is especially important that you attend to the first pulse of an episode. The typist frequently types, "have one" for "I have one," for example. It is not unusual for the typist to supply a preposition or article that the child has left out. At times, you will find it beneficial to count puises when you are uncertain as to whether to add a word or delete a word from the transcript.

A unit that starts as a question but ends as a statement is considered a single response unit statement. An episode that starts as a statement and ends as a question is considered a single response episode question (Example: 1 think 1 'll is okay to tell that man//).

Word and phrasal repetitions are excluded if they represent natural non-fiuencies as opposed to repeating for stress or elaboration. Vocal pauses are excluded. 


\section{APPENDIX D}

\section{SAMPLE TRANSCRIPT}

A: tell me what do you want for your birthday//

C: well you know what/

A: what//

C: one thing I can have/

A: well don't you want something special//

C: oh yes/

A: what/l

c: 1 don't know/

A: haven't you thought about it//

C: nof

A: aren't you going to ask for something of you know like a gun or/l

C: I al ready have a gun from Christmas/

A: oh/ well how about some cars//

c: you know what//

A: What//

c: I got two old guns/ one is rusty and one is a new one from Christmas/ two are new ones/

A: you have quite a few guns/ how'd the one get rusty//

C: wel! I don't know but that's why it got rusty/

A: doesn't it work any more//

C: nol 
A: that's too bad/

c: you know what//

A: what//

C: well a little later on 1 fixed it you know/

A: uh-huin//

c: and today 1 got it fixed/ my daddy fixed it/

A: well good/

C: and it did it/

A: you must have a pretty clever daddy/

c: yeah/ you know what// I got three guns/ one that has real bullets in it/

A: you're kidding/ really//

c: yeah/ you know what//

A: what//

C: my dadd' has a real gun but you know what// I'm just kidaing' you know what// one of my pop guns has coke bullets/

A: coke bullets//

c: you know those things that have to go in wine bottles/

A: oh cork/ yeah/

c: yeah/

A: that's right'

c: Well on the end of the string hooked to my shot gun/

A: Liri-hunil

c: and you have to cock it and you have to straighten it out/

A: uh-huh//

c: then you can shoot it/ pull the irigger and pop! 
A: and it pops out and you don't lose it cause it's hooked to the string/ that's great!

c: and the cork doesn't come off cause there's a knot there/

A: that's good so you won't lose it/ cause then you wouldn't have anything to shoot out the end of it would you/l

c: nol I'd just have to use it for a trigger/

A: yeah/ you'd just have to aim it but you wouldn't ever really get to shoot it/ and that wouldn't be much fun would it//

c: no that wouldn't be much fun/ but you know what//

A: what//

c: well/ one of my guns two of my guns shoot but the rusty one doesn't even shoot/

A: it doesn't//

C: huh-uh/ it's not a cork gun/

A: well you're lucky to have one cork guril

c: it's just plain/ the rusty one doesn't have no bullets in it/

A: nothing huh//

c: no/ but you know what//

A: what//

c: those corks in that shot gun dumb/ you can't shoot them/ cause when I get bigger 1111 have a real gun cause 1111 be bigger/

A: sure well! I don't think they let boys your age have real guns/

C: nol

A: does your daddy go hunting//

c: no not any more/ but you know what// when I get bigger me and my daddy will go hunting/ 
A: won't that be fun//

C: I never vent hunting so my daddy will have to teach me/

A: yeah well you can do that/ what do you think you want to hunt//

c: huh// you can hunt anything/ you can hunt the deer but deers aren't to eat/ buffalo are to eat/

A: some people eat deer/

C: but my baby eats turkey anything/

A: really/, how about youf/ what do you 1 ike to eat//

C: I like to eat peas and carrots/

A: yeah/

C: and I can't eat baby food/

A: you're too big for that/

C: yeah/

A: that would be kind of silly/

c: yeah/

A: how's about $1 /$

C: I like carrots and I like peas/

A: you like hamburgers/!

C: yeah I like hamburgers and bread and butter and I like roast/

A: uh-thuh/

c: chicken and a whole bunch of things/

A: that's great/ that's good/ you've got a good appetite/ you going to go home and have// have you already had your lunch//

c: yeah/

A: What did you have//

c: we had milk sandwich and I had a glass of milk/ 
A: two glasses of milk huh/i what kind of sandwich did you have/l

c: I have no sandwich/

A: what kirid//

C: I didn't have no sandwich/

A: you didn't have a sandwich// all you had was the milk//

C: I just had milk milk and water and water/ water and water and milk and milk/ that isn't lunch/ is it/l

A: no that's not lunch/ do you go to school//

c: yeah/ I got to nursery school/

A: what do you do at school all day//

C: we do all sorts of things/

A: tell me about them/

c: well we do/ we paint and we color and today we played with clayl

A: you've already been today/ did you make something//

$c:$ yeah but then I lefil that's all my school is/

A: that's all the longerl so did you not have time to finish up what you were making// that can be a problem sometimes/.

c: but it's all right cause you can come back there,

A: how many days do you go//

c: I go/ I beeri one day this week then we stay home all day I miss extra day so ! skip

A: you go every other day//

C: yean/

A: how do you get there//

c: my mormy takes me there/

A: oh/ you don't go on a school bus// do you want to play a little 
game!l well I kind of like to lcok at this book' do you know this book!!

c: yes/

A: tell me about the stories in this book will you//

C: what

A: 1 know/

c: a schooil/

A: a school// that's what lives in trees how come these can't live in trees//

C: cause they live in the zool

A: what are they//

C: elephant and a turtle/

A: $\mathrm{hm} /$

C: I just thinking/ what could be in here//

A: I don't know/ what do you think//

c: a frogl

A: Why can't these live in the pond//

C: cause the mice and the rats live in the zoo/

A: mice live in the zoo too// woops we've got two pages there/

c: what do you think will live in there/l

A: I haven't any idea/ a chipmunk/ what do you know about that// where do they live/l

C: they live in the zoo/ can I see what's in the other page/l

A: sure/ what is thatil

c: squirrel/ a house/ and let's see what's in here/ a lady bug/ 
A: riaht did you know that a lady bug is supposed to give you good luck/l

C: do you know what's in here/l

A: huhurh/ do you//

c: fish

A: I should have known fish would be in the water/ that makes sense doesn't it// le.t's.talk about these a minute/ could these live in the water//

c: no cause cats don't like water but dogs do/

A: that's right/ dogs do know how to swim don't they//

C: what's this// a lion and a bear live in the zoo/

A: that's for sure/

C: what do you think's in here//

A: I don't know/ do you know//

C: a bird that iays eggs'

A: yeah/ she's going to have some babies/

C: uh-huh/ what do you think's in there/l

A: I dori't know/

c: a worm/

A: à worm/ did you use a worm to catch your trout//

c: no we don't go fishing/

A: what about this one/i could it live under the rock//

C: no cause it lives in the seal it's a whale/

A: that's right/

c: what do you think's in herel!

A: I don't know/ let:s find out/ 
C: a familyl

A: a family/ you're right/ do those things caterpillars live in a house//

c: no/ they live outside/ and that's the end of the book/

A: okf do you know any letters// you spell your name so you can tell me what some of those letters are;

c: b/

A: uh-huh//

C: 81

A: uh-huh'

c: g/ of

A: good/ now watch/ what are those//

C: bu $u$ el

A: ok/

$c: \quad \underline{m k x /}$

A: yeah/ you even knew one upside down/

C: $\underline{x}$

A: that's upside down/ that's kind of hard to seel

c: $\quad x /$

A: these are all practically upside down/ that's a k/

c. $k /$ j/ $d /$ and $k /$

A: very good/ that's nice/ do you know any of these rhymes// hey diddle diddle//

C: $\underline{\text { nof }}$

A: why don't you tell me what's going on in that picture/

c: well the cow is gonna jump over the moon/ the cat gonna play the 
fiddle/ the dog is laughing/ and the plate is running away with the spoon/

A: do you really think that cow can jump over the moon// no/ it's just a story/

c: yeah/

A: what about this one//

C: I don't know that one/

A: what do you think she's doing//

C: baking a pie/

A: for the $\operatorname{dog} / /$

C: no/ dogs couldn't eat/ hey you know what//

A: what//

C: today we had a rabbit at nursery school/

A: what fun/

C: and I ran after it/

A: it was loose//

c: and yeah/

A: oh my goodness/

C: didn't tie it up or anything/

A: did you catch it//

c: no we couldin't/

A: was it soft//

C: yeah/ we could just pet it we couldn't chase it or it would get scared!

A: I see/ what coior was $i t / /$

C: white! 
A: how precty/

C: and it's ears was sort of pinky/ it was sort of pink/

A: it had kind of a pink wiggly noseil

C: why don't you set this book up//

A: ok/ you want to look at those//

C: yeah/ not this missing

A: you're right/ I wonder what happened to it/ do you think there's anything else missing about this doll//

C: nol

A: it doesn't have any arms/

C: no/

A: does it// I can't understand it/

C: it doesn't have legs and what else is it missing//

A: 1 don't know/

C: a forehead/

A: that's right Michael/ it doesn't have a forehead/

C: but do you know what else is missing//

A: what//

C: big toel

A: the toe' that doll doesn't have very many parts does $i t / /$

c: you can't see this cause it's all covered up/

A: uh-huh/ do you know what that is//

C: what//

A: that's a puppet/ you can stick your hand in there if you want to/ and talk to him/

C: he doesn't even talk/ 
A: you have to talk for him/ when you play with a puppet you have to talk for them/

c: you know what// this doesn't talk but you know what he wants to say//

A: what//

C: he says my uncle John he says that/

A: where do you watch the cookie monster//

C: on sesame Street/ he always says I want a cookie I want a cookie all the timel

A: does he get it//

C.: yeah/ but he doesn't say please/

A: he doesn't have nice manners huh//.

C: huh-uh/

A: he should say please/

c: yeah/

A: I think he'd stand a better chance of getting a cookie if he said please/

C: uhwhuh/ but the other time he/ sometimes he says I want a cookie and each time he wants a cookie they don't give him a cookie cause he doesn't say please/

A: that's the way it should be/ don't you thirk//

C: sometimes he says pleasel he says cookie please/

A: and that doesn't get it// well that's good/ nice manners are important/ what else do you see on Sesame Street// I've never seen that program/

C: weil you know what today I saw I don't know what I saw now I 
don't remember/ I didn't watch much of sesame street/

A: you didn't see much of Sesame street//

C: nol

A: do you see it at school//

c: yeah/ I'm going to kiss steven and 1111 be back in a minute/

A: oh wait just wait here a minute because 1 think we're just about finished and then you'll be able to goi 